\title{
Nanotubes: shaking hands, talking, or sharing?
}

\author{
Babak Javid ${ }^{1,2}$ and Keith M. Derbyshire ${ }^{3,4 *}$ \\ Department of Immunology and Infectious Diseases, Harvard School of Public Health, Boston, MA, USA \\ 2 Cambridge Institute for Medical Research, University of Cambridge, Cambridge, UK \\ ${ }^{3}$ Division of Genetics, Wadsworth Center, New York State Department of Health, Albany, NY, USA \\ ${ }^{4}$ Department of Biomedical Sciences, University at Albany, NY, USA \\ ${ }^{*}$ Correspondence: kmd08@health.state.ny.us
}

\section{A commentary on}

Intercellular nanotubes mediate bacterial communication

by Dubey, G. P., and Ben-Yehuda, S. (2011). Cell 144, 590-600.

Modern bacteriology was transformed by the ability to cultivate and grow pure cultures of organisms on media, which enabled the detailed and mechanistic study of physiology, biochemistry, and genetics. Whilst this reductionist approach was absolutely necessary to allow the molecular dissection and description of the fundamental processes of life, this mono-cultural focus meant that, until fairly recently, naturally occurring bacterial communities - complex, often multi-species populations - were the subject of less intensive study. Of course, that has all changed in the last few years. How microbes interact with members of their own species and those around them in a biofilm is one of the most exciting areas of microbiological research (Bassler and Losick, 2006; Kolter and Greenberg, 2006; Flemming and Wingender, 2010). Biofilms are not simply a tangled mass of different species: extensive research has shown that bacteria within the biofilm adapt and differentiate together in response to different nutritional and environmental stresses. The implication is that bacteria must "talk" to each other. Contact-independent mechanisms of bacterial communication - classical quorum sensing - were discovered in the 1960s, but recent work has shed light on more intimate, contact-dependent communication (Blango and Mulvey, 2009; Hayes et al., 2010).

Bacteria have developed a remarkable variety of intra-species contact-dependent signaling mechanisms (Hayes et al., 2010). C-signaling between the poles of Myxococcus xanthus cells promotes fruiting body formation and suppresses cell gliding (Nudleman et al., 2005). Cross-talk in B. subtilis between the mother cell and its forespore promotes differentiation to produce a dormant spore (Meisner et al., 2008). Contact-dependent inhibition is a reversible, contact-dependent means by which strains of $E$. coli induce a non-replicating state in susceptible cells through direct transfer of two effector proteins (Aoki et al., 2005). These three mechanisms are all characterized by the specific transfer of a limited number of signals in response to highly specific environmental cues between cells of the same species. However, bacteria can also communicate with other species. The first, and best-known, form of interspecies contactdependent trafficking is conjugation. Most conjugative plasmid transfer is restricted to specific species, but a subset of promiscuous plasmids can transfer between many different species and have a broad-host-range specificity (Thomas and Nielsen, 2005). Thus, although the substrate transferred is very specific, there is a relaxed specificity for recipients, which can be almost any bacterium or even eukaryotic cells (Buchanan-Wollaston et al., 1987; Heinemann and Sprague, 1989). Symbiotic relationships based on syntrophy also provide examples of inter-species contact-dependent communication (Ishii et al., 2005; Shimoyama et al., 2009). In the February 18th issue of Cell, Sigal BenYehuda's group now describes a new form of inter-bacterial communication: the transfer of cytoplasmic constituents through novel structures termed nanotubes. Remarkably, in contrast to the systems described above, there is no specificity in terms of the translocated substrate, the direction of transfer, or the species it is delivered to (Dubey and Ben-Yehuda, 2011).

In their potentially ground-breaking paper, Dubey and Ben-Yehuda (2011) show that Bacillus subtilis cells grown on solid medium can transfer multiple cytoplasmic contents to neighboring cells. They showed that B. subtilis could transfer green-fluorescent protein (GFP), the non-genetically encoded fluorophore calcein, a non-conjugative plasmid, as well as enzyme mediators of antibiotic resistance. The latter resulted in a transient, non-hereditary phenotypic resistance to antibiotic action. Remarkably, early signs of transfer were evident as quickly as $10 \mathrm{~min}$ after co-incubation. Highresolution scanning electron microscopy of cells grown on solid, but not liquid, media revealed tubular protrusions between adjacent cells, termed nanotubes by the authors. Both nanotube formation and non-hereditary transfer of antibiotic resistance were abolished by sub-inhibitory concentrations of the detergent SDS. The above correlations led the authors to hypothesize that translocation of these substrates was via the nanotubes. More direct evidence was presented by showing immuno-gold staining of GFP molecules within a nanotube. These nanotubes not only lacked substrate specificity, but also species specificity: nanotube connections were observed between three evolutionary distant bacterial species, B. subtilis, S. aureus, and E. coli.

By proposing that nanotubes actually mediate cytoplasmic exchange, the authors have challenged widely-held dogmas about the nature and purpose of both intra- and inter-species communication. As a consequence, their paper begs answers to questions about the structure of nanotubes, and who benefits from the transfer of intracytoplasmic contents. Even within multispecies bacterial communities, limited resources would lead to any one organism wishing ultimately to outcompete others. The multitude of soil-living organisms producing antibiotics, other secondary metabolites and toxins attests that even within complex biofilms, not everyone is friends. For the aforementioned examples of contact-dependent bacterial communication, there was a clear directionality of the communication, absolute substrate specificity, and a clear selective advantage. Even transfer of antibiotic resistance genes 
between species by classical conjugation can be explained by propagation of selfish DNA (Doolittle and Sapienza, 1980; Orgel and Crick, 1980). This cannot be true for transfer of non-genetic cytoplasmic contents. How is transfer within nanotubes regulated? Are the flood gates simply opened between cells? If all cytoplasmic contents are shared promiscuously, just like in any truly efficient market, any small advantage is rapidly negated.

The formation of nanotubes between Gram-positive and Gram-negative species poses further questions, particularly with regards to membrane topology. The authors show transfer of GFP from B. subtilis to $E$. coli. Presumably the nanotubes only connect to the outer membrane of E. coli, yet the micrographs show accumulation of fluorescent signal throughout the cell, suggesting internalization of the protein into the cytoplasm. The varying width $(30-130 \mathrm{~nm})$ and branching of nanotubes raises issues concerning their synthesis and function. Both conjugative pili and nanowires have far more homogenous architectures that are constrained by their protein subunits (e.g., pili are uniform in width and vary only slightly between different types, $6-11 \mathrm{~nm}$ wide; Bradley, 1980a,b). Traditionally, the assembly of structures that extend beyond the cell surface, such as pili and secretion systems, requires a sophisticated and highly coordinated machinery, not only to build the apparatus, but also to traverse recipient membranes and to ensure delivery of the substrate (Hayes et al., 2010). Further characterization of how nanotubes are synthesized and assembled, and the precise nature of the connection with the recipient, will no doubt be addressed in future studies. Use of split-GFP or -dihydro-folate-reductase molecular reporters, with or without tethering signals, would help address both the directionality and topology of the interbacterial communication.

We are intrigued by the fact that the nanotube observations were made at early time-points after mixing, at low cell densities, and on solid medium; conditions of early stages of biofilm formation. Indeed, this early time window may account for why it has taken so long for nanotubes to be described. Could it be that the primary purpose of these nanotube projections is to bind neighboring bacterial cells - a sort of 'shaking hands' on being introduced, as part of the initial steps of multi-species biofilm formation? As "hands" reach out and cells slide apart or divide, the tubes would be stretched and thus account for the varying tube widths. Certainly, other cellcell connections have also been shown to have important roles in biofim formation. Thin amyloid-like fibers provide structural integrity to B. subtilis biofilms (Romero et al., 2010). Conjugative pili are known to facilitate biofilm formation allowing for rapid transfer of plasmid DNA through the community (Ghigo, 2001; Reisner et al., 2006). Following the initial electrifying discovery of nanowires (Reguera et al., 2005), which act as electron conduits between Geobacter sulfurreducens cell membranes and $\mathrm{Fe}$ (III) oxide deposits, the "wires" were also shown to promote biofilm formation independently of electron transmission (Reguera et al., 2007).

Whether the primary purpose of nanotubes is the general transfer of cytoplasmic contents, the establishment of the earliest cell-cell contacts in biofilm formation, or some as yet uncharacterized function, their discovery by Dubey and Ben-Yehuda (2011) is certainly both exciting and fascinating. Further determining how sociable microbes like to be, what constitutes their conversations and whether after shaking hands, they do indeed become friends will no doubt be the subject of future study.

\section{ACKNOWLEDGMENTS}

Babak Javid is funded by the Medical Research Council (UK) and Keith M. Derbyshire receives funding from the NIH.

\section{REFERENCES}

Aoki, S. K., Pamma, R., Hernday, A. D., Bickham, J. E., Braaten, B. A., and Low, D. A. (2005). Contactdependent inhibition of growth in Escherichia coli. Science 309, 1245-1248.

Bassler, B. L., and Losick, R. (2006). Bacterially speaking. Cell 125, 237-246.

Blango, M. G., and Mulvey, M. A. (2009). Bacterial landlines: contact-dependent signaling in bacterial populations. Curr. Opin. Microbiol. 12, 177-181.

Bradley, D. E. (1980a). Determination of pili by conjugative bacterial drug resistance plasmids of incompatibility groups B, C, H, J, K, M, V, and X. J. Bacteriol. 141, 828-837.

Bradley, D. E. (1980b). Morphological and serological relationships of conjugative pili. Plasmid 4, 155-169.

Buchanan-Wollaston, V., Passiatore, J. E., and Cannon, F. (1987). The mob and oriT mobilization functions of a bacterial plasmid promote its transfer to plants. Nature 328, 172-175.
Doolittle, W. F., and Sapienza, C. (1980). Selfish genes, the phenotype paradigm and genome evolution. Nature 284, 601-603.

Dubey, G. P., and Ben-Yehuda, S. (2011). Intercellular nanotubes mediate bacterial communication. Cell 144, 590-600.

Flemming, H. C., and Wingender, J. (2010). The biofilm matrix. Nat. Rev. Microbiol. 8, 623-633.

Ghigo, J. M. (2001). Natural conjugative plasmids induce bacterial biofilm development. Nature 412, 442-445.

Hayes, C. S., Aoki, S. K., and Low, D. A. (2010). Bacterial contact-dependent delivery systems. Annu. Rev. Genet. 44, 71-90.

Heinemann, J. A., and Sprague, G. F. Jr. (1989). Bacterial conjugative plasmids mobilize DNA transfer between bacteria and yeast. Nature 340, 205-209.

Ishii, S., Kosaka, T., Hori, K., Hotta, Y., and Watanabe, K. (2005). Coaggregation facilitates interspecies hydrogen transfer between Pelotomaculum thermopropionicum and Methanothermobacter thermautotrophicus. Appl. Environ. Microbiol. 71, 7838-7845.

Kolter, R., and Greenberg, E. P. (2006). Microbial sciences: the superficial life of microbes. Nature 441, 300-302.

Meisner, J., Wang, X., Serrano, M., Henriques, A. O., and Moran, C. P. Jr. (2008). A channel connecting the mother cell and forespore during bacterial endospore formation. Proc. Natl. Acad. Sci. U.S.A. 105, 15100-15105.

Nudleman, E., Wall, D., and Kaiser, D. (2005). Cell-to-cell transfer of bacterial outer membrane lipoproteins. Science 309, 125-127.

Orgel, L. E., and Crick, F. H. (1980). Selfish DNA: the ultimate parasite. Nature 284, 604-607.

Reguera, G.,Mccarthy,K.D.,Mehta, T., Nicoll,J.S., Tuominen, M. T., and Lovley, D. R. (2005). Extracellular electron transfer via microbial nanowires. Nature 435, 1098-1101.

Reguera, G., Pollina, R. B., Nicoll, J. S., and Lovley, D. R. (2007). Possible nonconductive role of Geobacter sulfurreducens pilus nanowires in biofilm formation. J. Bacteriol. 189, 2125-2127.

Reisner, A., Holler, B. M., Molin, S., and Zechner, E. L. (2006). Synergistic effects in mixed Escherichia coli biofilms: conjugative plasmid transfer drives biofilm expansion. J. Bacteriol. 188, 3582-3588.

Romero, D., Aguilar, C., Losick, R., and Kolter, R. (2010). Amyloid fibers provide structural integrity to Bacillus subtilis biofilms. Proc. Natl. Acad. Sci. U. S. A. 107, 2230-2234.

Shimoyama, T., Kato, S., Ishii, S., and Watanabe, K. (2009). Flagellum mediates symbiosis. Science 323, 1574.

Thomas, C. M., and Nielsen, K. M. (2005). Mechanisms of, and barriers to, horizontal gene transfer between bacteria. Nat. Rev. Microbiol. 3, 711-721.

Received: 19April 2011; accepted: 19April 2011; published online: 02 May 2011.

Citation: Javid B and Derbyshire KM (2011) Nanotubes: shaking hands, talking, or sharing? Front. Microbio. 2:95. doi: 10.3389/fmicb.2011.00095

This article was submitted to Frontiers in Cellular and Infection Microbiology, a specialty of Frontiers in Microbiology.

Copyright (C) 2011 Javid and Derbyshire. This is an openaccess article subject to a non-exclusive license between the authors and Frontiers Media SA, which permits use, distribution and reproduction in other forums, provided the original authors and source are credited and other Frontiers conditions are complied with. 